\title{
Developing and Validating a Short Networking Behavior Scale (SNBS) from Wolff and
}

\section{Moser's (2006) measure}

\author{
Hans-Georg Wolff \\ University of Cologne
}

Daniel Spurk

University of Bern

Accepted Manuscript.

Wolff, H.-G. \& Spurk,D. (2020). Developing and Validating a Short Networking Behavior Scale (SNBS) from Wolff and Moser's (2006) measure. Journal of Career Assessment, 28 (2), 277-302. DOI: 10.1177/1069072719844924.

\section{Author Note}

Hans-Georg Wolff, Department of Psychology, University of Cologne; Daniel Spurk, Department of Psychology, University of Bern.

We would like to thank Julia Dühr and Jana Axmann for their help in data collection of Study 1 . Study 2 is part of a larger research project that has been supported by a grant from the German Ministry of Education and Research (BMBF, Number: 16FWN005). We would like to thank Anneke Dubbel, Luisa Barthauer, Vivien Estel, Mora Nixon, Philip Kaucher, and the whole project team for their help in project work and data collection.

Correspondence conderning this article should be addressed to: Hans-Georg Wolff, University of Cologne, Organisations- und Wirtschaftspsychologie, Bernhard-FeilchenfeldStr. 11., 50969 Köln, Germany.

E-Mail: Hans-Georg.Wolff@uni-koeln.de 


\begin{abstract}
Networking refers to building, maintaining, and using informal contacts to attain work or career resources. Although several measures exist, we are not aware of any short measure that reaches conventional standards and captures the breadth and multiple dimensions of the construct. To enable a brief and at the same time broad assessment of networking behaviors, this study reports the development and validation of a short version (the SNBS: Short Networking Behavior Scale) of Wolff and Moser's (2006) 44-item networking behavior scale. We examine the measurement properties of the derived 18-item version in two studies using three samples. Confirmatory factor analyses show that a correlated six-factor model with two higher-order factors of internal and external networking fits the data well. We provide evidence for construct and criterion-oriented validity showing that the internal and external networking scales exhibit meaningful correlational patterns with personality, career, and social network variables, but only small and mostly nonsignificant correlations with measures of job or task characteristics.
\end{abstract}

Keywords: networking, social capital, career competencies, scale development 


\section{Development and Validation of a Short Version of Wolff and Moser's Networking Behavior Scale}

The acquisition of resources from social contacts is a fundamental topic in the social and behavioral sciences. In organizational psychology and careers research, scholars have investigated networking behaviors, that is, building, maintaining, and using informal contacts to acquire resources that assist people in their work or career (for recent reviews see Gibson, Hardy, \& Buckley, 2014; Porter \& Woo, 2015). Networking refers to social behaviors with the goal to attain a large network of nonredundant contacts that facilitates the exchange of resources and favors (Wolff \& Moser, 2006). As proposed in theories on boundaryless (e.g., Arthur \& Rousseau, 1996) and protean careers (Hall, Yip, \& Doiron, 2018), scholars consider networking as an important career self-management strategy (Hirschi, Nagy, Baumeler, Johnston, \& Spurk, 2018). It is a means to attain outcomes such as salary (e.g., Blickle, Witzki, \& Schneider, 2009), promotions (e.g., Wolff \& Moser, 2010), career satisfaction (Ng \& Feldman, 2014), and getting a job (e.g., Van Hoye, Van Hoft, \& Lievens, 2009). Networking also yields work related resources that help people increase their work performance (Blickle et al., 2012) and it is related to well-being and reduced exhaustion on a daily level (Volmer \& Wolff, 2018).

Several instruments have been used to assess networking that range from single item measures (e.g., Casciaro, Gino, \& Kouchaki, 2014) to multidimensional measures of about 40 items (e.g., Forret \& Dougherty, 2001). In reviewing these scales, we found that in spite of the wide variety of scales, many of which possess desirable properties, every scale has its limitations (for recommendations on scale development see e.g., Hinkin, 1995; Nunnally, 1978; Wright, Quick, Hannah, \& Hargrove, 2017). First, there is the tradeoff between scale length and dimensionality. Short scales are typically unidimensional and preclude analyses of specific networking dimensions, whereas multidimensional scales are typically long and scholars might anticipate problems with subject responding due to long, tedious questionnaires (e.g., Stanton, Sinar, Balzer, \& Smith, 2002). Second, for many studies scholars developed ad hoc measures without much evidence for their validity (e.g., Casciaro et al., 2014; Sturges, Guest, Conway, \& Davey, 2002), and statistics for some measures do not 
reach conventional standards that are widely recommended in measurement theory (e.g., Porter, Woo, \& Campion, 2016). To our knowledge, a short high quality, multidimensional measure does not exist.

The aim of the present studies is therefore to provide a short, theoretically well-grounded multidimensional measure of networking behaviors and provide evidence for its validity. Specifically, we shorten Wolff and Moser's (2006) 44-item measure, which represents "the most comprehensive coverage of the networking construct space to date" (Porter \& Woo, 2015, p. 1480). We aim to reliably assess two prominent dimensions that are highly relevant in contemporary careers, which span within and across different organizations (Hall et al., 2018; Sullivan \& Baruch, 2009): internal and external networking that refer to a structural distinction of networking with people from one's own organization (i.e., coworkers) or other organizations, respectively (e.g., Michael \& Yukl, 1993; Porter, Woo, \& Campion, 2016). At the same time, we seek to preserve the breadth and construct coverage of the long version by using items that represent all other networking aspects (i.e., building, maintaining, and using social contacts). With regard to validity, we examine a wide range of antecedents and outcomes of networking, examining the measure's construct and criterion validity.

Our study's contribution is the provision of a psychometrically evaluated and time efficient means to assess dimensions of internal and external networking. This distinction is particularly useful for the study of differential relations of networking facets with other constructs and measures, for example internal and external career moves or turnover (e.g., Porter, Woo, \& Campion, 2016; Wolff \& Moser, 2010). Next to this methodological contribution, our study provides a sound basis for further theoretical work, such as investigating relations of internal versus external networking with other person, job, or career variables. The reliability and validity of measures is fundamental to draw substantive conclusions in any area of research (Hinkin, 1995) and we seek to provide this foundation within networking research.

\section{Networking: Conceptualization and Measurement}

\section{Conceptual Issues and Networking Dimensions}


Gibson and colleagues recently defined networking as "a form of goal directed behavior, both inside and outside an organization, focused on creating, cultivating, and utilizing interpersonal relationships" (2014, p. 150). Networking thus refers to behaviors and focuses on the individual level. Examples, taken from networking scales are introducing oneself to influential people (Sturges et al., 2002), socializing with colleagues after work (Forret \& Dougherty, 2001), or attending social events for professional purposes (Wolff \& Moser, 2006). The resulting networking relationships are informal, personal contacts that are characterized by trust (Michael \& Yukl, 1993) and a reciprocal exchange of resources (Porter \& Woo, 2015). The behavioral focus distinguishes networking from social capital that refers to characteristics of network structures such as network size or density on a structural level (see e.g., Adler \& Kwon, 2002; Burt, 1992). Yet, both concepts most likely affect each other as networking behaviors should lead to the creation of specific network structures and these should facilitate networking behaviors. In this vein, Wolff and Moser (2006) report that networking behaviors are associated with larger networks and lower network constraint, which refers to fewer connections between network contacts, thus facilitating information brokerage and innovation (Burt, 1992).

The definition in the previous paragraph and current theorizing (Gibson et al., 2014; Porter \& Woo, 2015) distinguishes two facets of networking behaviors. First, referring to a structural facet, networking contacts can belong to the same or another organization, labelled internal and external networking, respectively. A second, functional facet refers to the prototypical process of relationship development of building, maintaining, and using contacts. Scholars have suggested differential effects associated with these facets. For example, Porter and Woo (2015) have argued that people mostly exchange universalistic resources (e.g., money) when they build relationships and more particularistic resources (e.g., strategic information) when people have developed a stable relationship. Porter et al. (2016) have also shown that while internal networking is negatively related to turnover, external networking is positively related to turnover. Wolff and Moser (2010) report that effects of the facet of building, maintaining, and using contacts varies with time, that is, "contacts 
need to be developed in advance" (p. 243): building contacts did not predict immediate mobility events, but did so only for later events.

Concerning the nomological net of networking, Gibson et al. (2014) have summarized previous research in a model of antecedents and consequences. They identify three classes of antecedents, organizational level variables (e.g., organizational culture, industry), job characteristics (e.g., hierarchical level, job type), and individual differences (e.g., personality, career attitudes). Scholars have predominantly focused on individual antecedents, presumably because networking represents discretionary, informal behavior (Gibson et al., 2014; Porter \& Woo, 2015). Even though relations with contextual variables such as organizational variables or job characteristics are likely, they should not be a dominant antecedent. Rather relations with contextual variables should ideally exhibit weak to moderate relations, at best. With regard to consequences, Gibson et al. identified social capital as a proximal consequence, and several distal outcomes on an individual level (e.g., career success, visibility) and the organizational level (e.g., job performance, turnover).

\section{An Overview of Existing Networking Measures}

The variety of measures in the literature reflects the depiction of networking as a multifaceted construct that can be assessed at different levels of specificity. This depiction of the construct domain is similar, for example, to theories and measures on intelligence (e.g., Carroll, 1995), where general mental ability, but also specific subdimensions, such as memory span, logical reasoning, or verbal abilities can be identified. On a broad level, some unidimensional instruments assess a general higher-order factor of networking (e.g., Ferris et al., 2005), whereas on a lower level scholars have identified networking dimensions in an exploratory (e.g., Forret \& Dougherty, 2001) as well as in a deductive, theory driven manner (e.g., Wolff \& Moser, 2006).

Although each of the available networking measures has its own merits, we argue that they all have their limitations or deviate from best practices in scale development (Hinkin, 1995; Nunnally, 1978; Wright et al., 2017). This justifies the development and validation of an additional short and efficient multidimensional scale.

More specifically, some measures apply to certain groups such as entrepreneurs (Ebbers, 2014), managers 
(Michael \& Yukl, 1993), or unemployed persons (Van Hoye et al., 2009; Wanberg, Kanfer, \& Banas, 2000). These measures are not applicable to other groups, such as employed persons. Moreover, several measures focus on the single, higher-order dimension of networking (Casciaro et al., 2014; Ebbers, 2014; Ferris et al., 2005; Gould \& Penley, 1984; Hirschi et al., 2018; Sturges et al., 2002; Van Hoye et al., 2009; Wanberg et al., 2000). While these measures are usually short (e.g., the single item measure of Casciaro et al., 2014), they do not allow an examination of subdimensions or facets.

With regard to multidimensional measures, Forret and Dougherty (2001) developed a longer, 33-item measure. They derived items from qualitative interviews and used exploratory factor analysis to identify five dimensions in an inductive manner. The dimensions are (1) maintaining contacts, (2) socializing, (3) engaging in professional activities, (4) participating in church and community, and (5) increasing internal visibility. Forret and Dougherty (2001) also provide evidence for construct (e.g., extraversion, self-esteem) and criterion validity (e.g., number of promotions). However, some of the subscales of their measure possibly overlap with other career self-management dimensions, for example, their subscale increasing internal visibility appears closely related to the theoretical concept of visibility that has been described as a distinct dimension of CSM (e.g., Sturges et al., 2002). Also, the measure has a strong focus on maintaining contacts: None of the items appears to assess using contacts. In addition, recent theorizing has rarely focused on these dimensions and the measure thus appears less suited for the development of a short multidimensional scale.

Most multidimensional measures consist of dimensions of internal and external networking (Michael \& Yukl, 1993; Ng \& Feldman, 2010; Porter, Woo, \& Campion, 2016; Wolff \& Moser, 2006). Ng and Feldman (2010) only provide evidence for content and factorial validity. Although the scales are labelled internal and external social capital development behavior, items pertain to situational conditions (e.g., "at work I know a lot of people and am well connected"), behaviors ("I spend a lot of time and effort at work networking with others"), and competence-related self-ratings ("I am good at using my connections and networks to make things happen at work"). They therefore mix different concepts, which might blur the theoretical clarity of the 
construct and its content validity (Hinkin, 1995). In addition, the external social capital development behavior (i.e., external networking) items all refer to people in "my occupation". They thus exclude contacts to people from other domains such as politicians, people from the community, or fellow members from clubs such as Lions or Rotary.

Michael and Yukl (1993) used exploratory factor analysis to provide evidence for dimensions of internal and external networking of their managerial networking measure. The measure specifically focuses on managers and the authors do not discuss content validity. A brief inspection suggests that items mostly refer to maintaining and using contacts and some implicitly include building contacts (e.g., "attending trade shows and conferences"). With the exception of promotions received, their analyses - and implicitly their construct validation efforts - focused on situational determinants, that is, effects of dependencies or managerial function on networking behaviors. Networking behaviors probably depend to some degree on context, yet this should not be a defining feature, because as an individual difference, networking represents discretionary extra-role behaviors.

Wolff and Moser (2006) deductively developed a scale whose dimensions broadly cover the construct and its item universe (Porter \& Woo, 2015). All items refer to behaviors and respondents indicate how often they engage in these. In line with Wolff and Moser's theorizing and Gibson et al.'s (2014) consensus definition of networking, the items were developed to measure the structural (internal vs. external networking) and functional (building, maintaining, and using contacts) facets of networking. Crossing these facets, Wolff and Moser derived six subscales: (1) building internal contacts, (2) maintaining internal contacts, (3) using internal contacts, (4) building external contacts, (5) maintaining external contacts, and (6) using external contacts. Furthermore, the authors examined reliability (e.g. test-retest, internal consistency) and found evidence for the proposed structure in several studies using multidimensional scaling and confirmatory factor analysis in several cultures and languages (Gevorkian, 2011; Volmer, Orth, \& Wolff, 2017; Wolff \& Moser, 2006, 2009; Wolff, Rahm, \& Forret, 2011). Content validity was established by 5 networking experts and studies show evidence for 
validity, for example, the measure meaningfully relates to the five factor model of personality (Wolff \& Kim, 2012a), predicts salary growth (Wolff \& Moser, 2009) and internal and external networking differentially predict promotions and turnover, respectively (Wolff \& Moser, 2010). The measure is also associated with network size and network constraint (Wolff \& Moser, 2006), a finding that appears crucial, but, to our knowledge, has not been tested for any other measure.

Porter et al. (2016) have already aimed to derive a short measure of internal and external networking from Wolff and Moser's (2006) 44-item scale. They provide some evidence for construct validity indicating that correlations with the Big 5 personality are largely comparable for their short and the original 44-item version. However, concerning the internal scale structure they obtained fair results at best in two samples. Fit indices in confirmatory factor analyses did "not reach commonly accepted cut-off values" (p. 670, e.g. RMSEA =.10) and they obtained inadmissible solutions for some of their models (e.g., for a six factor model representing the six networking subscales). Whether the selected items adequately represent the latent dimensions of internal and external networking remains somewhat unclear.

In sum, we believe that of these multidimensional measures, some are too long (e.g., Wolff \& Moser, 2006), some appear to focus on specific facets of networking (e.g.,Michael \& Yukl, 1993), some confound different contents (e.g., $\mathrm{Ng} \&$ Feldman, 2010) or appear to cover highly specific regions of the construct domain (e.g., the participating in church and community scale of Forret \& Dougherty, 2001), and some have not been extensively validated (e.g., the single item measure of Casciaro et al., 2014).

\section{The Present Research}

Though many scholars have provided valuable work on networking assessment, we aim to take this research on and provide a short version of Wolff and Moser's (2006) multidimensional scale, the Short Networking Behavior Scale (SNBS). We believe the original measure's facets broadly cover the construct domain and there is evidence for construct as well as criterion validity, as noted in the previous section. However, participant time and effort is often scarce (cf. Rammstedt \& John, 2007) and the measure's length 
might prevent researchers from its use in larger research projects and those that take a range of constructs into account (Stanton et al., 2002). For example, in validating the career engagement scale, Hirschi, Freund, and Herrmann (2014) hypothesized relations of their measure with networking, but only used the 7-item subscale building external contacts, presumably because of survey length as they assessed eight additional constructs.

In the present study, we select items from this measure and conduct two studies with three samples to examine the newly derived SNBS in several ways. First, we examine the factor structure. Wolff and Moser $(2006,2009)$ have examined several models and found that a correlated six-factor model representing the six combinations of the two facets fit their 44-item measure well. Moreover, they argued that a single second-order factor was a more parsimonious representation of the correlations between the six first-order factors. Note, however, that they did not examine other higher-order factor models, as for instance a model distinguishing internal from external networking. Here we aim to establish a brief measure of the structural facet of internal vs. external networking, because it appears important for contemporary research in careers and, accordingly, this distinction has received the most scholarly interest (Michael \& Yukl, 1993; Ng \& Feldman, 2010; Porter, Woo, \& Campion, 2016; Wolff \& Moser, 2010). We assume that factors of internal and external networking represent the underlying constructs either on a first-order (i.e., six correlated factors of which three represent internal and external networking, respectively) or on a higher-order level. In the latter case, the six subscales represent firstorder factors, and internal and external networking are second-order factors. This latter model was not examined by Wolff and Moser (2006).

Second, building upon theorizing and empirical evidence from prior research, we examine the validity of the SNBS. With regard to construct validity, we predict that the SNBS will be related to several personality traits (e.g., the five factor model of personality, self-monitoring) and career constructs (e.g., protean career orientation, career commitment) that serve as antecedents of networking (Gibson et al., 2014). Additionally, because networking refers to individual, discretionary behavior, we seek to show that job characteristics do not dominate (individual) differences in SNBS scores. With regard to criterion validity, we examine whether the 
measure relates to network structure and to important career outcomes, such as career satisfaction or marketability.

\section{Study 1: Item Selection, Psychometric Properties, and Initial Validation}

In this study, we report item selection, an initial test of the psychometric properties, and an initial examination of the measure's validity. With regard to construct validity, we sought to replicate positive relations of networking with extraversion (Forret \& Dougherty, 2001; Wolff \& Kim, 2012a), self-monitoring (Ferris et al., 2005), self-esteem (Forret \& Dougherty, 2001), and achievement motivation (Wolff \& Moser, 2006). We also examined job and task characteristics assuming small or small to medium effects. Specifically, we examined the relation between networking and hierarchical position, task interdependency, and autonomy. We assume that those higher in organizational hierarchies and those with more interdependent tasks might interact with more persons due to formal requirements of their jobs. Yet, networking, as an informal, discretionary behavior should not be fully determined by such organizational requirements. Similarly, autonomy provides people with discretion on how they do their jobs (Hackman \& Oldham, 1976), which might facilitate, but should not predominantly determine networking. In this vein, we suggest that individual differences explain more variance in networking behaviors than task and contextual variables. Finally, as a first measure of criterion validity, we examine career satisfaction, as Ng and Feldman's (2014) meta-analysis provides evidence for an association between this career outcome and networking.

\section{Method}

We describe the selection of items in the subsequent section. To examine the selected items, this study uses two samples. Specifically, in Sample 1, we only measured the 18 networking items and a few demographic variables, whereas in Sample 2, we additionally examined the validity of the networking scales by assessing its relations with other constructs. In the present analyses, we combine the two samples to examine the factor structure using an adequate sample size. In addition, we use only data from Sample 2 to examine the validity of the networking scales. 
Item Selection. In line with recommendations by Stanton et al. (2002), we selected items using (a) internal item qualities, that is, statistical indices such as item factor loadings or item-total correlations and (b) judgmental criteria, that, for example, take item wording and content validity into account and require subjective judgment. Stanton et al. caution to rely on statistical indices alone, because this might yield items that merely paraphrase each other and might fail to represent the original construct domain. Therefore, our first decision was to preserve the breadth of the measure and the facets by selecting a comparable number of items from each of Wolff and Moser's (2006) six subscales. We presumed that a reliable scale would be attainable with three items from each subscale (Hinkin, 1995), that is nine items assessing each, internal and external networking, respectively. Second, as an internal item quality criterion, we obtained raw data for the 44-item long version from the studies by Wolff and Kim (2012a, N=371), Wolff and Kim (2012b, $N=355)$, and Wolff, Weikamp, and Batinic $(2018, \mathrm{~N}=707) .{ }^{1}$ We use all three datasets to select items thus reducing the dependability of our selection on a single sample and its particularities. We ran several factor analyses on the full item sets and also on only the internal and external items, respectively. Inspecting the results, we rank ordered items according to the highest average loading on its respective factor across the datasets, taking high cross-loadings on other factors into account as well. The resulting table of item wordings and data was then presented to a panel of three experts (i.e., one doctoral student working on a dissertation in the careers domain and two professors in organizational psychology who had also published on networking and careers). These scholars selected the items based on the rank-order and additional judgmental concerns raised in a discussion, mostly related to content validity, breadth of construct coverage, and item similarity (Stanton et al., 2002). For example, they decided to drop the item “At company events or outings I approach colleagues I haven’t met before" in spite of its high loading, because it is highly similar to the item "I use events in my organization to make new contacts" that remained in the shortened version. The panel also decided to adapt the wording of

\footnotetext{
${ }^{1}$ Note that we used raw data on the 44 networking items only and no additional information. Sample sizes in the original studies are smaller than the ones we use, because the authors typically excluded participants for a range of reasons (e.g., missing data in other variables, information on employment).
} 
some items in order to clarify (rather than change) the meaning of the items. They revised some seemingly oldfashioned or rarely used wordings (e.g., "in my business" was changed to "in my organization") and some specific terms (e.g., "business trips / training events" into the broader "external events"). As some of the original internal networking items only implicitly focused on contacts within a person's organization, the panel added an explicit reference to a person's own organization if necessary (the scale is available from the first author upon request).

Sample 1. A professional market research company recruited 180 persons for a short study on professional contacts. Participants, restricted to full time workers, were randomly drawn from the company's German online access panel. They received the standard compensation of the company for short surveys (i.e., $0.50 €$, about US\$ 0.70; median completion time was 3 min 15 s). From the 180 recruited persons, 10 participants aborted the questionnaire; six did not fulfill the requirement of fulltime work (i.e. $>30$ hours per week, see e.g., Forret \& Dougherty, 2001), and 27 exhibited insufficient effort responding as they took either too short (i.e., less than 1s per item, see e.g., Huang, Curran, Keeney, Poposki, \& DeShon, 2012) or too long (i.e., more than two hours) to complete the questionnaire. The resulting sample size was 137 persons, with 71 males $(52 \%)$ and 66 females $(48 \%)$. The mean age of participants was 43.6 years $(S D=10.99)$. According to the International standard classification of education (UNESCO Institute for Statistics, 2012), 49 (36\%) had obtained tertiary education, 35 (26\%) had upper secondary, and $52(38 \%)$ lower secondary education. On average, participants worked $42.08 \mathrm{hr}$ per week $(S D=7.82)$. Their mean organizational tenure was 12.7 years $(S D=10.37)$ and $45(32 \%)$ were in a supervisor position.

Sample 2. Two graduate students recruited a convenience sample (e.g., acquaintances, calls for participation in mailing lists) for an online survey on organizational behavior in Germany. ${ }^{2}$ To reduce common method bias (Podsakoff, MacKenzie, \& Podsakoff, 2012), we assessed the validation measures (at T1) and networking (at T2) one week apart. Two hundred thirty nine persons accessed the first questionnaire and 162

\footnotetext{
${ }^{2}$ Note that in this sample we also assessed three items intended to measure organic - mechanistic organizational structure. However the scale did not prove reliable $(\alpha=.58)$ and we thus do not report findings here.
} 
participants (68\%) completed it and left their email address to be invited for the second part of the study. One week later, we contacted 159 persons (reduction due to three invalid email addresses) and 142 persons completed the second part of the survey (89\%). Email addresses were kept separate from the substantive data and matching was done with a personalized code participants entered in both surveys. We excluded 19 persons for several reasons, that is, matching problems (five persons), insufficient effort responding (seven persons who took longer than 120 and 60 minutes for either 78 items at T1 or 23 items at T2, respectively), limited working hours (six persons working less than $20 \mathrm{hr}$ per week), and missing data in study variables (one person). The resulting sample size was 123, with 53 males (43\%) and 70 females (57\%) and an average age of 38.4 years $(S D$ $=12.47)$. The majority of participants $(n=74$ or $60 \%)$ had obtained tertiary education, $31(25 \%)$ had upper secondary, 18 (15\%) lower secondary education, 95 (77\%) were married, and 33 (27\%) had children. Their mean organizational tenure was 8.9 years $(S D=9.02)$, and $34(28 \%)$ were in a supervisor position. The majority of participants ( $n=95$ or $77 \%$ ) worked full time (i.e., more than 30 hours per week), and 28 participants (23\%) worked part time $(20$ - $30 \mathrm{hr}$ per week.

\section{Measures.}

Measures used in Sample 1. In Sample 1, we assessed networking with the selected items in their German version using a 5-point Likert scale $(1=$ never/ rarely, $5=$ very often / always $)$. Sample items are "I discuss upcoming organizational changes with colleagues from other departments of my organization" (internal networking) or "I use external events to build new contacts with persons from other organizations." (external networking). To provide a sample description (see section Sample 1 above), we assessed gender, age, education, weekly working hours, job experience, and whether participants were in a supervisor position.

Measures used in Sample 2. In Sample 2, we assessed networking with the selected items that we will briefly refer to as short networking behavior scale (SNBS), and also several scales to examine the validity of the new measure. We also assessed several organizational and demographic variables to describe the sample (see section Sample 2 above). 
Networking. We assessed networking with the 18 item SNBS described in the section on item selection using a 5-point Likert scale $(1=$ never/ rarely, 5 = very often / always $)$.

Extraversion. We measured the disposition to be sociable, cheerful, and energetic with the German version of the 12-item NEO FFI Extraversion scale (Borkenau \& Ostendorf, 2008, sample item "I like to have many people around me"). Participants answered the items on a five-point Likert scale ranging from strongly disagree to strongly agree. This questionnaire has been extensively used and validated in Germany, for example, Borkenau and Ostendorf (2008) reported evidence for convergent validity as the measure meaningfully correlated with other extraversion scales and Körner et al. (2008) reported adequate internal consistency in a representative sample. Summarizing the research evidence, Kanning (2009) stated that the measure fulfills "all criteria relevant for diagnostic instruments" (p. 197, own translation). The internal consistency in this study was $\alpha=.78$.

Self-monitoring. We used Snyder and Gangestad's (1986) 18-item scale to assess people's ability to "observe and control expressive behavior and self-presentation" (p. 125). This is the most prominent measure in spite of its low internal consistency (rarely exceeding .70, cf. Lennox \& Wolfe, 1984) and a long debate on its factor structure (Gangestad \& Snyder, 2000; Lennox \& Wolfe, 1984; Snyder \& Gangestad, 1986). Sample items are "I would probably make a good actor" and "I may deceive people by being friendly when I really dislike them". Respondents indicated whether items applied to them on a dichotomous true - false scale. Snyder and Gangestad provided a thorough overview on the validity of the scale. They reported, for example, that high selfmonitors perform well in boundary spanning jobs that require the adaptation of behavior to a variety of situations, or that low self-monitors' friendship choices reflect shared values and interests, whereas high selfmonitors take status, which represents the value others attach to their friends, into account. In the present study, internal consistency was somewhat low, $\alpha=.66$, yet in line with other studies using the scales (Lennox \& Wolfe, 1984; Tasselli \& Kilduff, 2018; Wolff \& Moser, 2006). 
Self-esteem. Self-esteem, that is, the favorability of people's attitude toward themselves was assessed with the 10-item scale by Rosenberg (1965, sample items "I certainly feel useless at times", "I feel that I have a number of good qualities") using a four-point Likert scale $(1=$ does not apply to me, 4 = fully applies to me $)$. Research supports the scale's reliability and factor structure across a range of nations (Schmitt \& Allik, 2005), including Germany (Roth, Decker, Herzberg, \& Brähler, 2008). For the German version, Ferring and Fillip (1996) reported adequate reliability and meaningful relations with dispositional optimism, self-efficacy, wellbeing, and hopelessness. Using an attachment framework, Schmitt and Allik found positive associations with internal working models of the self, and no association with working models of others. The internal consistency estimate in this study was $\alpha=.82$.

Achievement motivation. The achievement motive refers to the striving to do things better and aim for success and performance. We used a scale taken from Modick (1977) in its shortened 7-item version by Goebel and Frese (1999, sample items "I believe it is important to perform better than others", "When I have started a difficult task, it is hard to stop working on it"), using a four-point Likert scale $(1=$ strongly disagree, $4=$ strongly agree). Modick provided evidence for discriminant and convergent validity of the long version, for example that it correlates highly with other measures of achievement motivation. Others reported positive associations of the shortened version with personal initiative (Frese, Fay, Hilburger, Leng, \& Tag, 1997) and entrepreneurial success (Goebel \& Frese, 1999), and Wolff and Moser (2006) reported significant correlations between the shortened version and their networking scales. In this study, the internal consistency was satisfactory $(\alpha=.77)$.

Subjective career success. We used two items from Abele and Spurk (2009) that assess other-referent subjective career success according to Heslin (2005). We used people with similar education and age as referent groups (e.g., "Compared with other people in your age group, how successful do you think your career development has been so far?') and participants indicated their judgment on a seven-point Likert scale $(1=$ much less successful, $7=$ much more successful). Abele and Spurk have extensively examined this measure and 
report adequate internal consistency and adequate malleability across time, as well as a positive association with salary. Spurk and Volmer (2013) showed that the measure exhibits positive correlations with self-referent subjective career satisfaction, career optimism, and salary. The internal consistency in our study was $\alpha=.79$.

Task interdependence. The 3-item measure assesses the amount of interdependence or cooperation required to accomplish individuals' work tasks and was taken from a measure of work group design by Campion, Medsker, and Higgs (1993). We employed a five-point Likert scale $(1=$ strongly disagree $5=$ strongly agree), a sample item is "I cannot accomplish my tasks without information or materials from other members of my team". Campion et al. reported high interrater agreement among work group members. The measure also correlated positively with communication within, but not between teams and was positively related to social support. Though the internal consistency was somewhat low in their original study (i.e., $\alpha=$ $.61)$, it is satisfactory in the present study $(\alpha=.71)$, possibly because their sample came from a single organization and might suffer from range restriction.

Autonomy. We assessed the discretion individuals have in deciding when and how to complete their work tasks by four items taken from the short questionnaire for job analysis from Prümper, Hartmannsgruber, and Frese (1995, sample item "I can plan and schedule my work by myself"). Participants answered these items on a five-point Likert scale $(1=$ to a very little extent, $5=$ to a very high extent $)$. Factor analyses by Prümper et al. and also Cohrs, Abele, and Dette (2006) showed that the items form a meaningful construct that is distinct from other job characteristics such as task variety, variability, or opportunities for participation. Keller and Semmer (2013) found that the measure positively correlates with core self-evaluations and predicts job satisfaction (see also Cohrs et al., 2006). The reliability estimate in this study is $(\alpha=.79$.

Hierarchy. We followed Blickle et al. (2009) in assessing the level of people's position in the company hierarchy with a single item. Specifically, we asked respondents to adjust a slider ranging from 1 (bottom) to 100 (top) to indicate their position in the organizational hierarchy. In their study, this measure exhibited meaningful correlations with salary, gender, and intelligence, and was also related to a unidimensional 
networking measure. Mölders, Brosi, Spörrle, and Welpe (2017) reported that the measure correlates with holding a leadership position, and also with gender, age, and education.

Analyses. We combined both samples for a sample size on $N=260$ to examine the scale structure by means of confirmatory factor analyses. We used the robust ML estimation of LISREL 8.7 (Jöreskog \& Sörbom, 1996). To establish model fit, we follow recommendations by $\mathrm{Hu}$ and Bentler (1999) using a combined criterion of SRMR $<0.09$ and $\mathrm{CFI}>0.95$ that was also used by Wolff and Moser (2006). In addition, we report RMSEA, where values below .08 are considered favorably (see e.g., Williams, Vandenberg, \& Edwards, 2009). Because these indices always show better fit of more complex models, we used the PNFI (Mulaik, James, Van Alstine, \& Bennett, 1989) and CAIC to evaluate differences in models, if more than one model satisfied our fit criteria. Next to absolute model fit, these indices also take model parsimony into account and the CAIC also allows the comparison of nonnested models (Bozdogan, 1987; Jöreskog \& Sörbom, 1996). There are no absolute cut-offs for these indices, but higher values in PNFI and lower values in CAIC indicate better models in terms of model fit and parsimony.

We examine the validity using data from Sample 2 only. With a sample size of $n=123$, the power to obtain significant correlations $(\alpha=.05$, one-tailed) for small $(|r|=.10)$ and medium $(|r|=.30)$ effects is Power $=$ 0.30 and Power $=0.96$, respectively (Cohen, 1988). In addition, we interpret the relevant correlations as effect sizes.

\section{Results and Discussion}

Table 1 shows the results from confirmatory factor analyses of both samples for seven models. The first six of these models have been previously examined by Wolff and Moser (2006). Model 1 represents a single factor model (all 18 items load on one first-order factor) that does not fit the data well as all indices fail to satisfy conventional criteria of fit. Models 2 and 3 consist of one of the two facets, that is either two factors of internal or external networking (Model 2) or three factors of building, maintaining, and using contacts (Model 3). According to all fit indices, neither model exhibits satisfactory fit. A five-factor model (Model 4), 
representing the two facets separately as five factors fits the data well as does a six-factor model (Model 5). Note that the six-factor model (Model 5) has fewer parameters than Model 4 and is therefore more parsimonious as indicated by a higher PNFI and lower CAIC for Model 5. With regard to the first-order factor structure, the six-factor model (Model 5) is thus the best fitting model.

Models 6 and 7 are higher-order factor models that model the correlations between the six first-order factors of Model 5 in a more parsimonious way. Model 6 proposes a single higher-order factor and Model 7 proposes two higher-order factors that represent internal and external networking. Both models exhibit good absolute fit, with the two-factor model (Model 7) being preferable according to the CAIC. In comparison to Model 5 with six correlated factors, both models are preferable according to the PNFI, but not according to the CAIC. Note that there is only a slight difference between the six factor model $5(\mathrm{CAIC}=584.09)$ and model 7 with two higher-order factors $(\mathrm{CAIC}=585.51)$. We therefore conclude that a six-factor model fits the data well, and that the correlations between these factors can be explained by two higher-order factors of internal and external networking. Figure 1 depicts this model.

Table 2 exhibits descriptive statistics and reliabilities for the six first-order and two higher-order scales. To avoid redundancy, Table 2 shows findings from all samples in this paper. With regard to the two higherorder factors of internal and external networking, internal consistency estimates are well above .70 (Hinkin, 1995; Nunnally, 1978). However, with regard to the first-order factors the internal consistency estimate for maintaining internal contacts in sample 2 is slightly below this threshold.

With regard to validity, findings from sample 2 were mostly supportive (see Table 3 ). As predicted, the SNBS scales show positive associations with personality measures of extraversion, achievement motivation (and self-monitoring), and also with career satisfaction. However, self-esteem was not significantly related to both networking scales. With regard to job characteristics, only the correlation of autonomy with internal networking was significant $(r=.18, p=.042)$. With regard to their absolute size, most correlations of the SNBS with these job and task variables were small or small to medium at best (i.e., $r \leq .20$ ). 
To further examine the contribution of individual vs. job and task characteristics, we ran a hierarchical multiple regression controlling for age and gender in a first step (see Table 4). Entering the three job and task variables in a second step explained a significant $R^{2}=.09, F(3,116)=4.16, p=.010$ in internal networking and an insignificant $R^{2}=.03, F(3,115)=1.26, p=.29$ in external networking. Adding the four personality variables to the regressions in Step 3, these explained an additional $\Delta R^{2}=.12, F(4,112)=4.54, p=.002$, in internal networking and an additional $\Delta R^{2}=.10, F(4,111)=4.29, p=.014$, in external networking. These results show that job and task characteristics explain some variance in networking behaviors, but individual variables explain incremental variance over and above these variables. They also suggest that individual variables might explain more variance in networking than job and task characteristics. Note that achievement motivation and extraversion exhibit significant parameters in these models and are thus the main drivers of the personality networking relation. Coefficients for self-monitoring were not significant, possibly, because this variable has conceptual overlap with extraversion (Gangestad \& Snyder, 2000) or the lower reliability of the present measure.

In sum, a model with two higher order factors of internal and external networking appears to fit the data well and simultaneously represents a parsimonious solution. In comparison to Porter et al. (2016) the present SNBS exhibits a substantively meaningful factor structure with adequate model fit. Although we primarily intended to obtain broad and reliable measures of internal and external networking, the first-order factors (distinction between building, maintaining, and using contacts) seem to allow a reliable assessment of six dimensions.

Findings concerning validity are promising (i.e., 8 out of 10 correlations were significant), although the SNBS measure was unrelated to self-esteem. In Forret and Dougherty's (2001) original study self-esteem was only related to three of the five networking dimensions (i.e., increasing internal visibility, engaging in professional activities, and maintaining contacts), and these dimensions might not be represented as clear in our scales. Finally, going beyond the relation between managerial dependencies and networking (Michael \& Yukl, 
1993), this is the first study to show that personality variables might explain more variance in networking than situational variables, though we did not attempt an exhaustive sampling of situational variables for a complete picture of this issue. We consider the temporal separation of the measures as a unique strength of this study.

\section{Study 2: A large Sample Replication}

This study seeks to replicate the factor structure and has two validity foci. First, we further establish construct validity and seek to replicate associations of networking, assessed by the SNBS, with the full fivefactor model of personality. In their review, Gibson et al. (2014) report that networking is positively related to extraversion and openness to experience and negatively to neuroticism. As these authors report mixed findings with regard to agreeableness and conscientiousness, we will explore these relations. In addition, given the theorizing on the importance of networking for career self-management in times of boundaryless and protean careers (Sturges et al., 2002), we assume that SNBS is positively related to career commitment, as well as boundaryless and protean career attitudes (Hall et al., 2018; Porter, Woo, \& Tak, 2016). A second focus is on criterion validity. Because networking should lead to large and diverse networks, we examine participant's network structure and suggest that the SNBS positively correlates with network size and negatively with network constraint (Burt, 1992). In addition, as networking should result in positive assessments of the career and career prospects, we propose that networking exhibits positive associations with internal and external marketability (Eby, Butts, \& Lockwood, 2003), and career satisfaction (Ng \& Feldman, 2014; Spurk, Hirschi, \& Dries, 2019).

\section{Method}

Data was collected as part of a larger research project that examined careers of young researchers in Germany (e.g., research associates or postdoctoral researchers). In Germany, doctoral students as well as postdocs are typically employed by universities or research institutions, but work on temporary contracts until they attain one of the few tenured professor or lecturer positions, or move to private industry employers. We extensively advertised the study at research institutions (e.g., at university registration offices for PhDs, mailing 
lists). Ads contained a link to the project's website with additional information on the study and 1,533 individuals followed our request to register for participation by entering their email address. They subsequently received a personalized invitation for an online survey to which 1,268 (82\%) responded. From those participants, we excluded 114 participants that did not work in science, 205 participants that did not complete the questionnaire, 12 participants who worked less than $20 \mathrm{hr}$ per week, and 44 participants with missing data in study variables for a final sample size of $N=893$. There were slightly more females (468 or $52 \%)$ than males (425 or $48 \%)$ in the sample. Participants' mean age was 33.3 years $(S D=5.54)$, and $57 \%$ held a doctoral degree.

Due to the length of the survey, we administered the network questionnaire as an additional questionnaire that participants could answer on a later occasion. Reducing concerns of common method bias, it is thus temporally separated from the assessment of the networking questionnaire (Podsakoff et al., 2012). We obtained 511 responses on the network questionnaire.

Measures. If not stated otherwise, all measures used a six-point Likert scale $(1=$ does not apply, $6=$ fully applies).

Networking. We assessed networking with the shortened 18-item SNBS.

Career commitment. We used the affective career commitment scale from Felfe, Schmook, and Six (2006). The measure assesses people's affective attitudes toward or the perceived attachment to their career. The scale consists of five items; a sample item is "My career has great personal meaning to me". In their original study, the authors reported a reliability of $\alpha=.79$ for this scale, and high but distinct relations to other commitment foci (e.g., organization, supervisor). Moreover, CFAs supported the construct and discriminant validity of the measure. Spurk, Hirschi, and Kauffeld (2016) reported positive correlations with external career goals and high work investments. In this study, the internal consistency of the scale was $\alpha=.81$.

Protean and boundaryless career attitudes. We used two of four short scales for these constructs developed by Porter et al. (2016). The 4-item protean career self-directed (PCSD) scale assesses people's self- 
direction in their pursuit of (psychological) career success and the 3-item boundaryless career organizational mobility preference (BCOMP) scale assesses individuals' attitude toward a change of employer in their future career. Sample items for the scales are "Where my career is concerned, I am very much "my own person"” and "I prefer to stay in a company I am familiar with rather than look for employment elsewhere", respectively. Porter and colleagues reported evidence for the factorial structure and the validity of the scales in three studies. For example, both scales correlated with openness to experience, and the PCSD, but not the BCOMP is positively related to proactivity. Also, The PCSD and BCOMP exhibited positive and negative correlations, respectively, with organizational commitment. The internal consistency for both scales was $\alpha=.80$.

Marketability. We assessed beliefs that one is valuable to the current or other employers with Eby et al.'s (2003) internal and external marketability scales, respectively. Each scale consists of three items, sample items are "My company views me as an asset to the organization" and "There are many jobs available for me given my skills and experience", respectively. Eby et al. showed that the scales load on distinct factors and are also distinct from perceived career success. In addition, they showed that the scales are meaningfully related to the perceived possession of career-related skills, and career satisfaction. De Vos, De Hauw, and van der Heijden (2011) found high correlations with a measure of employability, and Spurk and Volmer (2013) showed that the scales are positively related to job market knowledge, salary, and career optimism. Reliabilities in the present study were acceptable with $\alpha=.77$ and $\alpha=.81$ for internal and external marketability, respectively.

Career satisfaction. We measured career satisfaction defined as individuals perceptual evaluations of their sequence of work experiences over time with the 5-item scale by Greenhaus, Parasuraman, and Wormley (1990). Sample items are "I am satisfied with the progress I have made toward meeting my goals for the development of new skills" and "I am satisfied with the success I have achieved in my career". The measure has been extensively used in careers research and appears to be among the most prominent measures of career satisfaction in the literature (e.g., De Vos et al., 2011; Eby et al., 2003; Hirschi et al., 2014; Hirschi et al., 2018; Spurk et al., 2019). Wolff and Moser (2009) showed that their long version networking scale predicts 
differences in this measure and that it is positively associated with, but distinct from salary. In the present study, the measure also correlates with Turban and Dougherty's (1994) measure of perceived career success, $r=.69, t$ $(890)=28.76 p<.001$, that we assessed, but omit from the analyses, because the two are highly redundant. In the present study, the Greenhaus et al. scale exhibited an internal consistency of $\alpha=.81$.

Personality. The traits from the five factor model of personality, that is, extraversion, neuroticism, openness for experience, agreeableness, and conscientiousness (McCrae \& Costa, 1997), were measured with the German Ten-Item Personality Inventory (TIPI-G, Muck, Hell, \& Gosling, 2007). The scale utilizes two items to assess each trait, sample items are, "extraverted, "enthusiastic" or "reserved, quiet" (reversed) for extraversion and "dependable, self-disciplined" or "conventional, uncreative" (reversed) for conscientiousness and openness, respectively. Relating the five factors to self and peer ratings of other measures of the Big Five, Muck et al. provided evidence for the convergent and discriminant validity of the scales. Erhart et al. (2009) reported similar findings and meaningful correlations of the five traits with self-monitoring, locus of control, life satisfaction, and trait anxiety. Similarly, Romero, Villar, Gomez-Fraguela, and Lopez-Romero (2012) found supportive evidence for the TIPI's factor structure, its construct validity and test-retest reliability. Internal consistencies in our study range from .83 for extraversion to .38 for agreeableness (see Table 6) and are comparable, at times somewhat higher than those Muck et al. reported. Note that internal consistency is not an adequate estimator of reliability for these short and broad scales and usually retest reliabilities for these scales are more adequate (e.g., Rammstedt \& John, 2007; Romero et al., 2012).

Network measures. Following Dobrow and Higgins' (2005) assessment of developmental networks, we asked participants to list up to 15 contacts (e.g., colleagues, friends, or kin) that supported them in their career by means of a name generator question. We slightly extended the name generator applied by Dobrow and Higgins by providing more example behaviors (e.g., provide information or create career opportunities) of possible supporters to facilitate the name gathering for participants. The number of people listed represents a measure of Network size. In a second step, participants received a matrix of the contacts they listed and 
indicated whether their contacts knew each other. Network constraint is a summary measure that taps the extent of connections between contacts (Burt, 1992). It reflects the non-redundancy of contacts that is more likely, when contacts are not connected to each other, as opposed to cliques, where contacts of a focal person typically know each other, and information flows are redundant (Burt, 1992). We standardized values to range from 0 (low constraint) to 1 (high constraint, see e.g., Burt, 1992). Using name generator questions and matrices of contacts among contacts is the most prominent way to assess ego-centered networks (e.g., Burt, 1992; Burt, Janotta, \& Mahoney, 1998; Dobrow \& Higgins, 2005; Higgins \& Kram, 2001; Podolny \& Baron, 1997; Seibert, Kraimer, \& Liden, 2001; Wolff \& Moser, 2006). Burt et al. provided evidence that network size and constraint are related to extraversion and Wolff and Moser (2006) reported that networking is associated with network size and network constraint. Seibert Kraimer, and Liden (2001) showed that constraint is indirectly associated with measures of career success.

Analyses. As in Study 1, we conducted a CFA using robust ML and rely upon the combined criterion of SRMR $<0.09$ and $\mathrm{CFI}>0.95$ to evaluate model fit. As more than one model satisfied this fit criterion, we used the PNFI and CAIC to evaluate differences in models, taking parsimony into account, as well. With regard to validity, we examined correlation coefficients, using one-tailed tests. With a sample size of $N=893(n=511$ for the network measures), the power to obtain significance $(\alpha=.05)$ for small $(|r|=.10)$ and medium $(|r|=.30)$ effects is Power $=0.91$ ( 0.73 for the network measures) and Power $>0.99$ (also for network measures), respectively (Cohen, 1988).

\section{Results and Discussion}

Confirmatory factor analyses showed that Models 1 to 3 with a single, two, or three first-order factors, respectively, did not obtain adequate fit (see Table 5). A model with five first-order factors (Model 4) and a model with six first-order factors (Model 5) fit the data well. As the models are nonnested, the CAIC shows that the six-factor model exhibits better fit than the five factor model. In additional models, simplifying the correlations between the six first-order factors by means of higher-order factors, Model 7 with two higher order 
factors (i.e., internal and external networking) fit well and better than Model 6 with a single higher-order factor according to the CAIC and the PNFI. Table 2 shows reliabilities for all factors. With the exception of maintaining internal contacts $(\alpha=.65)$, all reliabilities were satisfactory (i.e., above .70).

Table 6 depicts correlations of the SNBS scales with validity criteria. Four of the six career variables exhibited small to medium (i.e., . $10<r<.30$ ) and significant correlations with the networking scales. The correlations of boundaryless career attitudes with internal networking and of protean career attitudes with external networking were smaller, albeit significant. In sum, these findings show that the networking scales are meaningfully related to career attitudes and subjective career outcomes. As predicted, networking was also positively related to extraversion and openness to experience and negatively related to neuroticism. There were no significant correlations with conscientiousness or with agreeableness. Finally, networking was positively related to network size and negatively to network constraint, indicating that those who network also report larger and more diverse networks with fewer connections between contacts.

In sum, we found additional support for a six-factor model with two higher-order factors of internal and external networking. Overall, the pattern of correlations largely follows our presumptions. A distinct strength of the present study is its large sample size and the broad range of validity coefficients presented here. A limitation is the focus on researchers, predominantly employed in universities. For example, participants are highly educated and this might limit generalizability to less educated persons, because education positively affects networking (Gibson et al., 2014). The sample also carries the risk of range restriction. Note however, that some correlations, for example the correlation between internal and external networking, or the correlation between networking and extraversion closely correspond to the results from Study 1 and appear not to be affected by the nature of the sample. In addition, Study 1 has provided some evidence that job and organizational characteristics affect the SNBS scales only to a small or small to medium extent. This provides some, albeit limited evidence against generalizability concerns. Yet, future research should take these into account. 


\section{General Discussion}

With this research, we provide a short scale, the SNBS, which assesses internal and external networking. With regard to absolute fit a correlated six-factor model fit the data best in both studies. Taking parsimony into account, as well, we propose that two higher-order factors represent the underlying constructs of our scales. Note however, that the differences between the best fitting models are small and future research needs to corroborate our presumption of two higher-order factors. The latent correlations between the two factors $(\rho=$ .75 and $\rho=.63$, in Studies 1 and 2, respectively) indicate that the two dimensions are distinct but highly related. This finding is not fully in line with Wolff and Moser's (2006) finding of a single higher-order factor for the original long version. However both scales operate on the same basis of six first-order factors and these authors did not examine models with two higher-order factors. Also, given the prominence of the internal - external distinction, we selected items with the specific aim to establish two distinct scales. Similar to research on intelligence, we suggest that it is viable to collapse the internal and external networking scales into an index of general networking. Though it was not the primary goal of the study, the SNBS might be a viable option to examine the first-order factors that separate building, maintaining, and using social contacts, as well. However, scholars should be cautioned that the reliability of maintaining internal contacts might not reach conventional standards. A potential explanation is our broader sampling of items to evade highly similar items only paraphrasing each other (Stanton et al., 2002).

We also present broad evidence for the validity of the SNBS. Possibly most important, we show that the scales are in fact associated with specific network structures. In this vein, our measure is helpful in relating individual behaviors to structural level network characteristics, a topic that has been largely neglected in research on networking as well as social network research. With regard to personality, we were able to replicate previous findings, indicating that networking is associated with extraversion, openness to experience, and neuroticism. In addition, given that networking represents a strategy of career self-management, we provide evidence that the SBNS scales are meaningfully related with other measures tapping career management (e.g., 
career commitment) and its outcomes (e.g., marketability, career satisfaction). Finally, we also show that the SBNS scores are not simply a function of job or task characteristics. Even though scholars implicitly assume that networking is discretionary extra role behavior, the extent to which networking is determined by the situation (i.e., job/ task characteristics) or the person has remained largely unexplored. Here we provide some evidence, but acknowledge that further research into this question is necessary.

We believe that the SBNS is a valid and viable means to assess networking in a range of situations. We recommend using it when participant time (e.g., in large scale surveys with many constructs) or attention (e.g., in online surveys) is limited (Stanton et al., 2002). Also, when studies focus on networking in general or theorizing relies upon the distinction of internal vs. external networking, the SBNS might be a good choice (Porter, Woo, \& Campion, 2016). The original long version allows a more detailed examination of the functional facet of building, maintaining, and using contacts. Studies focusing on specific facets may fare better with a subscale of the long version. In addition, we recommend the long version for studies that examine changes in or the timing of networking behaviors, for example before and after mobility events, because they most likely will show on the functional facet. We also recommend the long version for individual feedback, for example in networking trainings, because the higher number of items provides a richer sample of networking behaviors for discussion.

\section{Limitations}

We consider our thorough efforts to examine the psychometric properties as a distinct strength of this research. Yet, our studies are not without limitations. In this regard, as our samples came from Germany, cultural concerns might limit generalizability of the scales to other cultures. We thus caution scholars to consider cultural fit when using the SNBS. Note however, that the long version has been used in a variety of cultures, such as the U.S. (Wolff et al., 2011), China (Volmer et al., 2017), or the UK (Wolff \& Kim, 2012a) and we are thus optimistic that this also holds for the short version presented here. Also, our findings focus on the overall validity of the SBNS, but do not attempt to provide evidence for differential relations of the internal 
and external networking scales with other criteria. While several scholars have found such effects (e.g., Porter, Woo, \& Campion, 2016; Wolff \& Kim, 2012a), they often rely on specific combinations of both the functional and the structural facet that we cannot fully disentangle with our short measure. Finally, as noted by a reviewer, correlations that we take as evidence for the validity of the scales yield effects of medium size, at best (i.e., the median validity coefficient across the two studies is $r=.19$ ). Note however, that these effect sizes are largely in line with findings from other studies, for example, the (corrected) meta-analytic correlation between career satisfaction and networking (i.e., $r=.24, \mathrm{Ng} \&$ Feldman, 2014) is comparable to our correlations (i.e., $r=.23$ and $r=.20$ for internal and external networking, respectively).

\section{Conclusion}

The SBNS and its scales provide a reliable, valid, and timesaving measurement of networking behaviors and allow distinguishing the structural facet of internal and external networking. We believe that the development based upon a theoretically derived measure and the data presented from three samples provide a sound basis for future research that helps overcome the threat of flawed measures (Hinkin, 1995). 


\section{References}

Abele, A. E., \& Spurk, D. (2009). How do objective and subjective career success interrelate over time? Journal of Vocational Behavior, 82, 803-824. doi: 10.1348/096317909X470924

Adler, P. S., \& Kwon, S.-W. (2002). Social capital: Prospects for a new concept. Academy of Management Review, 27, 17-40. doi: 10.5465/AMR.2002.5922314

Arthur, M. B., \& Rousseau, D. M. (1996). The boundaryless career. New York: Oxford University Press.

Blickle, G., John, J., Ferris, G. R., Liu, Y., Haag, R., Meyer, G., Weber, K., \& Oerder, K. (2012). Fit of political skill to the work context: A two-study investigation. Applied Psychology: An International Review, 61, 295-322. doi: 10.1111/j.1464-0597.2011.00469.x

Blickle, G., Witzki, A. H., \& Schneider, P. B. (2009). Self-initiated mentoring and career success: A predictive field study. Journal of Vocational Behavior, 74, 94-101. doi: 10.1016/j.jvb.2008.10.008

Borkenau, P., \& Ostendorf, F. (2008). NEO Fünf-Faktoren Inventar nach Costa und McCrae. Göttingen: Hogrefe.

Bozdogan, H. (1987). Model selection and Akaike Information Criterion (AIC): The general theory and its analytical extensions. Psychometrika, 52, 345-370.

Burt, R. S. (1992). Structural holes. Cambridge, MA: Harvard University Press.

Burt, R. S., Janotta, J. E., \& Mahoney, J. T. (1998). Personality correlates of structural holes. Social Networks, 20, 63-87. doi: 10.1016/S0378-8733(97)00005-1

Campion, M. A., Mesdker, G. J., \& Higgs, A. C. (1993). Relations between work group characteristics and effectiveness: implications for designing effective group work. Personnel Psychology, 46, 823-847. doi: 10.1111/j.1744-6570.1993.tb01571.x

Carroll, J. B. (1995). On methodology in the study of cognitive abilities. Multivariate Behavioral Research, 30. doi: 10.1207/s15327906mbr3003_6 
Casciaro, T., Gino, F., \& Kouchaki, M. (2014). The contaminating effects of building instrumental ties: Hoiw networking can make us feel dirty. Administrative Science Quarterly, 59, 705-735. doi: $10.1177 / 0001839214554990$

Cohen, J. (1988). Statistical power analysis for the behavioral sciences (2nd ed.). Hillsdale, NJ: Erlbaum.

Cohrs, C. J., Abele, A. E., \& Dette, D. (2006). Integrating situational and dispositional determinants of job satisfaction: Findings from three samples of professionals. The Journal of Psychology, 140, 363-395. doi: 10.3200/JRLP.140.4.363-395

De Vos, A., De Hauw, S., \& van der Heijden, B. I. J. M. (2011). Competency development and career success: The mediating role of employability. Journal of Vocational Behavior, 79, 438-447. doi: 10.1016/j.jvb.2011.05.010

Dobrow, S. P., \& Higgins, M. C. (2005). Developmental networks and professional identity: A longitudinal study. Career Development International, 10, 567-583. doi: 10.1108/13620430510620629

Ebbers, J. J. (2014). Networking behavior and contracting relationships among entrepreneuers in business incubators. Entrepreneurship Theory and Practice, 38, 1159-1181. doi: 10.1111/etap.12032

Eby, L. T., Butts, M., \& Lockwood, A. (2003). Predictors of success in the era of the boundaryless career. Journal of Organizational Behavior, 24, 689-708. doi: 10.1002/job.214

Erhart, M. G., Holcombe Erhart, K., Roesch, S. G., Chung-Herrera, B. G., Nadler, K., \& Bradshaw, K. (2009). Testing the latent factor structure and construct validity of the Ten-Item Personality Inventory. Personality and Individual Differences, 47, 900-905. doi: 10.1016/j.paid.2009.07.012

Felfe, J., Schmook, R., \& Six, B. (2006). Die Bedeutung kultureller Wertorientierungen für das Commitment gegenüber der Organisation, dem Vorgesetzten, der Arbeitsgruppe und der eigenen Karriere [The relevance of cultural value orientations to organizational, supervisor, team, and career commitment]. Zeitschrift für Personalpsychologie, 5, 94-107. doi: doi:10.1026/1617-6391.5.3.94 
Ferring, D., \& Filipp, S.-H. (1996). Messung des Selbstwertgefühls: Befunde zur Reliabilität, Validität und Stabilität der Rosenberg-Skala [Assessment of self esteem: evidence for reliability, validity, and stability of the Rosenberg-scale]. Diagnostica, 42.

Ferris, G. R., Treadway, D. C., Kolodinsky, R. W., Hochwarter, W. A., Kacmar, C. J., Douglas, C., \& Frink, D. D. (2005). Development and validation of the political skill inventory. Journal of Management, 31, 126152. doi: $10.1177 / 0149206304271386$

Forret, M. L., \& Dougherty, T. W. (2001). Correlates of networking behavior for managerial and professional employees. Group and Organization Management, 26, 283-311. doi: 10.1177/1059601101263004

Frese, M., Fay, D., Hilburger, T., Leng, K., \& Tag, A. (1997). The concept of personal intiative: Operationalization, reliability, and validity in two German samples. Journal of Occupational and Organizational Psychology, 70, 137-161. doi: 10.1111/j.2044-8325.1997.tb00639.x

Gangestad, S. W., \& Snyder, M. (2000). Self-monitoring: Appraisal and reappraisal. Psychological Bulletin, 126, 530-555. doi: 10.1037//0033-2909.126.4.530

Gevorkian, M. (2011). Relationships between proactive personality, networking, career satisfaction, and performance percetions. Unpublished Dissertation. Alliant International University. San Diego, CA.

Gibson, C., Hardy, J. H. I., \& Buckley, R. M. (2014). Understanding the role of networking in organizations. Career Development International, 19, 146-161.

Goebel, S., \& Frese, M. (1999). Persönlichkeit, Strategien und Erfolg bei Kleinunternehmern [Personality, strategies, and success of small business entrepreneurs]. In K. Moser, B. Batinic \& J. Zempel (Eds.), Unternehmerisch erfolgreiches Handeln (pp. 93-113). Göttingen: Hogrefe.

Gould, S., \& Penley, L. E. (1984). Career strategies and salary progression: A study of their relationships in a municipal bureaucracy. Organizational Behavior \& Human Performance, 34, 244-265. doi: $10.1016 / 0030-5073(84) 90006-0$ 
Greenhaus, J. H., Parasuraman, S., \& Wormley, W. M. (1990). Effects of race on organizational experiences, job performance evaluations, and career outcomes. Academy of Management Journal, 33, 64-86. doi: $10.2307 / 256352$

Hackman, J. R., \& Oldham, G. R. (1976). Motivation through the design of work: Test of a theory. Organizational Behavior \& Human Performance, 16, 250-279.

Hall, D. T., Yip, J., \& Doiron, K. (2018). Protean careers at work: Self direction and value orientation in psychological success. Annual Review of Organizational Psychology and Organizational Behavior, 5, 129-156. doi: 10.1146/annurev-orgpsych-032117-104631

Heslin, P. A. (2005). Conceptualizing and evaluating career success. Journal of Organizational Behavior, 26, 113-136. doi: 10.1002/job.270

Higgins, M. C., \& Kram, K. E. (2001). Reconceptualizing mentoring at work: A developmental network perspective. Academy of Management Review, 26, 264-298. doi: 10.5465/AMR.2001.4378023

Hinkin, T. R. (1995). A review of scale development practices in the study of organizations. Journal of Management, 21, 967-988.

Hirschi, A., Freund, P. A., \& Herrmann, A. (2014). The career engagement scale: Development and validation of a measure of proactive career behaviors. Journal of Career Assessment, 22, 575-594. doi: $10.1177 / 1069072713514813$

Hirschi, A., Nagy, N., Baumeler, F., Johnston, C. S., \& Spurk, D. (2018). Assessing key predictors of career success: Development and validation of the career resources questionnaire. Journal of Career Assessment, 2018, 2. doi: 10.1177/1069072717695584

Hu, L.-T., \& Bentler, P. M. (1999). Cutoff criteria for fit indices in covariance structure analysis: Conventional criteria versus new alternatives. Structural Equation Modeling, 6, 1-55. doi: $10.1080 / 10705519909540118$ 
Huang, J. L., Curran, P. G., Keeney, J., Poposki, E. M., \& DeShon, R. P. (2012). Detecting and deterring insufficient effort responding in surveys. Journal of Business and Psychology, 27, 99-114. doi: 10.1007/s10869-011-9231-8

Jöreskog, K., \& Sörbom, D. (1996). Lisrel 8 users' reference guide. Chicago, Il: Scientific Software International.

Kanning, U. P. (2009). Neo-Fün-Faktoren-Inventar nach Costa und McRae (NEO-FFI) [NEO-Five-FactorInventory by Costa and McCrae (NEO-FFI)]. Zeitschrift für Arbeits- und Organisationspsychologie, 53, 194-198. doi: 10.1026/0932-4089.53.4.194

Keller, A., \& Semmer, N. (2013). Changes in situational and dispositional factors as predictors of job satisfaction. Journal of Vocational Behavior, 83, 88-98. doi: 10.1016/j.jvb.2013.03.004

Körner, A., Drapeau, M., Albani, C., Geyer, M., Schmutzer, G., \& Brähler, E. (2008). Deutsche Normierung des NEO-Fünf-Faktoren-Inventars [German norms for NEO-Five-Factor-Inventory]. Zeitschrift für Medizinische Psychologie, 17.

Lennox, R. D., \& Wolfe, R. N. (1984). Revision of the self-monitoring scale. Journal of Personality and Social Psychology, 46, 1349-1364. doi: 10.1037/0022-3514.46.6.1349

McCrae, R. R., \& Costa, P. T. J. (1997). Personality trait structure as a human universal. American Psychologist, 52, 509-516. doi: 10.1037/0003-066X.52.5.509

Michael, J., \& Yukl, G. (1993). Managerial level and subunit function as determinants of networking behavior in organizations. Group and Organization Management, 18, 328-351. doi: 10.1177/1059601193183005

Modick, H.-E. (1977). Ein dreiskaliger Fragebogen zur Erfassung des Leistungsmotivs - Bericht über eine deutschsprachige Weiterentwicklung des Prestatie Motivatie Test. Diagnostica, 23, 298-321.

Mölders, S., Brosi, P., Spörrle, M., \& Welpe, I. M. (2017). The Effect of Top Management Trustworthiness on Turnover Intentions via Negative Emotions: The Moderating Role of Gender. Journal of Business Ethics. doi: 10.1007/s10551-017-3600-9 
Muck, P. M., Hell, B., \& Gosling, S. D. (2007). Construct validation of a short five-factor model instrument: A self-peer study on the German adaptation of the ten-item personality inventory (TIPI-G). European Journal of Psychological Assessment, 23, 166-175. doi: 10.1027/1015-5759.23.3.166

Mulaik, S. A., James, L. R., Van Alstine, J., \& Bennett, N. (1989). Evaluation of goodness-of-fit indices for structural equation models. Psychological Bulletin, 105, 430-445. doi: 10.1037/0033-2909.105.3.430

Ng, T. W. H., \& Feldman, D. C. (2010). The effects of organizational embeddedness on development of social capital and human capital. Journal of Applied Psychology, 95, 696-712. doi: 10.1037/a0019150

Ng, T. W. H., \& Feldman, D. C. (2014). Subjective career succes. A meta-analytic review. Journal of Vocational Behavior, 85, 169-179. doi: 10.1016/j.jvb.2014.06.001

Nunnally, J. C. (1978). Psychometric theory (2nd ed.). New York: McGraw-Hill.

Podolny, J. M., \& Baron, J. N. (1997). Resources and relationships: Social networks and mobility in the workplace. American Sociological Review, 62, 673-693.

Podsakoff, P. M., MacKenzie, S. B., \& Podsakoff, N. P. (2012). Sources of method bias in social science research and recommendations on how to control it. Annual Review of Psychology, 63, 539-569. doi: 10.1146/annurev-psych-120710-100452

Porter, C., M., \& Woo, S. E. (2015). Untangling the networking phenomenon: A dynamic psychological perspective on how and why people network. Journal of Management, 41, 1477-1500. doi: $10.1177 / 0149206315582247$

Porter, C., M., Woo, S. E., \& Campion, M. A. (2016). Internal and external networking differentially predict turnover through job embeddedness and job offers. Personnel Psychology, 69, 635-672. doi: $10.1111 /$ peps. 12121

Porter, C., M., Woo, S. E., \& Tak, J. (2016). Developing and validating short form protean and boundaryless career attitudes scales. Journal of Career Assessment, 24, 162-181. 
Prümper, J., Hartmannsgruber, K., \& Frese, M. (1995). KFZA - Kurzfragebogen zur Arbeitsanalyse [KFZA - A short questionnaire for job analysis]. Zeitschrift für Arbeits- und Organisationspsychologie, 39, 125-132.

Rammstedt, B., \& John, O. P. (2007). Measuring personality in one minute or less: A 10-item short version of the Big Five Inventory in English and Germen. Journal of Research in Personality, 41, 203-212. doi: 10.1016/j.jrp.2006.02.001

Romero, E., Villar, P., Gomez-Fraguela, A., \& Lopez-Romero, L. (2012). Measuring personality traits with ultra-short scales: A study of the Ten Item Personality Inventory (TIPI) in a Spanish sample. Personality and Individual Differences, 53, 289-293. doi: 10.1016/j.paid.2012.03.035

Rosenberg, M. (1965). Society and the adolescent self-image. Princeton, NJ: Princeton University Press.

Roth, M., Decker, O., Herzberg, P. Y., \& Brähler, E. (2008). Dimensionality and norms of the Rosenberg selfesteem scale in a German general population sample. European Journal of Psychological Assessment, 24, 190-197. doi: 10.1027/1015-5759.24.3.190

Schmitt, D. P., \& Allik, J. (2005). Simultaneous administration of the Rosenberg self-esteem scale in 53 nations: Exploring the universal and culture-specific features of global self-esteem. Journal of Personality and Social Psychology, 89, 623-642. doi: 10.1037/0022-3514.89.4.623

Seibert, S. E., \& Kraimer, M. L. (2001). The five factor model of personality and career success. Journal of Vocational Behavior, 58, 1-28. doi: 10.5465/APBPP.1999.27594943

Seibert, S. E., Kraimer, M. L., \& Liden, R. C. (2001). A social capital theory of career success. Academy of Management Journal, 44, 219-237. doi: 10.2307/3069452

Snyder, M., \& Gangestad, S. W. (1986). On the natrue of self-monitoring: Matters of assessment, matters of validity. Journal of Personality and Social Psychology, 51, 125-139. doi: 10.1037/0022-3514.51.1.125

Spurk, D., Hirschi, A., \& Dries, N. (2019). Antecedents and outcomes of objective versus subjective career success: Competing perspectives and future directions. Journal of Management, 45, 35-69. doi: $10.1177 / 0149206318786563$ 
Spurk, D., Hirschi, A., \& Kauffeld, S. (2016). A new perspective on the etiology of workaholism. The role of personal and contextual career-related antecedents. Journal of Career Assessment, 24, 747-764. doi: $10.1177 / 1069072715616127$

Spurk, D., \& Volmer, J. (2013). Validierung einer deutschsprachigen Version des Career Futures Inventory (CFI) [Validation of a German version of the Career Futures Inventory (CFI)]. Zeitschrift für Arbeitsund Organisationspsychologie, 57, 77-95. doi: 10.1026/0932-4089/a000106

Stanton, J. M., Sinar, E. F., Balzer, K. W., \& Smith, P. C. (2002). Issues and strategies for reducing the length of self-report scales. Personnel Psychology, 55, 167-194. doi: 10.1111/j.1744-6570.2002.tb00108.x

Sturges, J. J. L., Guest, D., Conway, N., \& Davey, K. M. (2002). A longitudinal study of the relationship between career management and organizational commitment among graduates in the first ten years at work. Journal of Organizational Behavior, 23, 731-748. doi: 10.1002/job.164

Sullivan, S. E., \& Baruch, Y. (2009). Advances in career theory and research: A critical review and agenda for further exploration. Journal of Management, 35, 1542-1571. doi: 0.1177/0149206309350082

Tasselli, S., \& Kilduff, M. (2018). When brokerage between friendship cliques endangers trust: A personalitynetwork fit perspective. Academy of Management Journal, 61, 802-825. doi: 10.5465/amj.2015.0856

Turban, D. B., \& Dougherty, T. W. (1994). Role of protégé personality in receipt of mentoring and career success. Academy of Management Journal, 37, 688-702.

UNESCO Institute for Statistics. (2012). International standard classification of education. Montreal: UNESCO Institute for Statistics.

Van Hoye, G., Van Hoft, E. A. J., \& Lievens, F. (2009). Networking as a job search behavior: A social network perspective. Journal of Occupational and Organizational Psychology, 82, 661-682. doi: $10.1348 / 096317908 X 360675$ 
Volmer, J., Orth, M., \& Wolff, H.-G. (2017). Multidimensional networking behavior in Germany and China: Measurement invariance and associations with objective career success. Journal of Career Assessment. doi: $10.1177 / 1069072717723302$

Volmer, J., \& Wolff, H.-G. (2018). A Daily Diary Study on the Consequences of Networking on Employees' Career-Related Outcomes: The Mediating Role of Positive Affect. Frontiers in Psychology, 9, 2129. doi: 10.3389/fpsyg.2018.02179

Wanberg, C. R., Kanfer, R., \& Banas, G. T. (2000). Predictors and outcomes of networking intensity among unemployed job seekers. Journal of Applied Psychology, 85, 491-503. doi: 10.1037//00219010.85 .4 .401

Williams, L. J., Vandenberg, R. J., \& Edwards, J. R. (2009). Structural equation modeling in management research: A guide for improved analysis. Academy of Management Annals, 3, 543-604. doi: 543-604doi: $10.1080 / 19416520903065683$

Wolff, H.-G., \& Kim, S. (2012a). The relationship between networking behaviors and the Big five personality factors. Career Development International, 17, 43-66. doi: 10.1108/13620431211201328

Wolff, H.-G., \& Kim, S. (2012b). What are the costs of networking? developing and testing assumptions in work and nonwork domains. Paper presented at the Academy of Management Conference, San Antonio, TX.

Wolff, H.-G., \& Moser, K. (2006). Entwicklung und Validierung einer Networkingskala [Development and validation of networking scale]. [Development and validation of a networking scale]. Diagnostica, 52, 161-180. doi: 10.1026/0012-1924.52.4.161

Wolff, H.-G., \& Moser, K. (2009). Effects of networking on career success: A longitudinal study. Journal of Applied Psychology, 94, 196-206. doi: 10.1037/a0013350

Wolff, H.-G., \& Moser, K. (2010). Do specific types of networking predict specific mobility outcomes? A twoyear prospective study. Journal of Vocational Behavior, 77, 238-245. doi: 10.1016/j.jvb.2010.03.001 
Wolff, H.-G., Rahm, C., \& Forret, M. L. (2011). Adaptation of a German multidimensional networking scale into English. European Journal of Psychological Assessment, 27, 244-250. doi: 10.1027/10155759/a000070

Wolff, H.-G., Weikamp, J., \& Batinic, B. (2018). Implicit motives as determinants of networking behaviors. Frontiers in Psychology, 9:411. doi: 10.3389/fpsyg.2018.00411

Wright, T. A., Quick, J. C., Hannah, S. T., \& Hargrove, B. M. (2017). Best practice recommendations for scale construction in organizational research: The development and initial validation of the Character Strength Inventory (CSI). Journal of organizational Behavior, 38, 615-628. doi: 10.1002/job.2180 
Table 1

Results from Confirmatory Factor Analysis in Study 1

\begin{tabular}{lcllllc}
\hline & Chi $^{2}(\mathrm{df})$ & RMSEA & SRMR & CFI & PNFI & CAIC \\
\hline 1) 1 factor & $836.35(135)$ & 0.140 & 0.097 & 0.89 & 0.77 & 1072.54 \\
2) 2 factors (internal vs. external) & $564.58(134)$ & 0.110 & 0.078 & 0.94 & 0.80 & 807.33 \\
$\begin{array}{l}\text { 3) } 3 \text { factors (building, maintaining, } \\
\text { using) }\end{array}$ & $724.90(132)$ & 0.130 & 0.092 & 0.91 & 0.77 & 980.76 \\
4) 5 factors $^{\mathrm{a}}$ & & & & & & \\
5) 6 factors $^{\mathrm{b}}$ & $225.90(113)$ & 0.062 & 0.046 & 0.98 & 0.71 & 606.42 \\
6) 6 factors $^{\mathrm{b}}$ and 1 G-factor & $249.50(120)$ & 0.065 & 0.051 & 0.98 & 0.76 & 584.09 \\
7) 6 factors $^{\mathrm{b}} \& 2$ G-factors (internal vs. \\
external $^{3}$
\end{tabular}

Note. Samples 1 and 2 were combined for $N=260$.

${ }^{a}$ This model represents within item multidimensionality with two sets of factors: a) two correlated factors of internal vs. external networking and b) three correlated factors of building, maintaining, and using contacts.

However, the two sets are uncorrelated (e.g., no correlation between internal networking and building contacts).

$\mathrm{b}$ The six factors are (1) building internal contacts, (2) maintaining internal contacts, (3) using internal contacts, (4) building external contacts, (5) maintaining external contacts, and (6) using external contacts. 
Table 2

Internal Consistency and Descriptive Statistics for Subscales of all three Samples

\begin{tabular}{|c|c|c|c|c|c|c|}
\hline & \multicolumn{2}{|l|}{ Sample 1} & \multicolumn{2}{|l|}{ Sample 2} & \multicolumn{2}{|l|}{ Sample 3} \\
\hline & $M(S D)$ & $\alpha$ & $M(S D)$ & $\alpha$ & $M(S D)$ & $\alpha$ \\
\hline Internal networking total & $3.19(0.68)$ & .85 & $3.39(0.64)$ & .84 & $4.30(0.89)$ & .85 \\
\hline External networking total & $2.69(0.84)$ & .93 & $2.83(0.77)$ & .91 & $4.16(1.09)$ & .91 \\
\hline \multicolumn{7}{|l|}{ Internal networking } \\
\hline Building & $3.03(0.89)$ & .76 & $3.26(0.84)$ & .74 & $4.11(1.14)$ & .75 \\
\hline Maintaining & $3.22(0.79)$ & .75 & $3.39(0.71)$ & .63 & $4.32(0.96)$ & .65 \\
\hline Using & $3.33(0.82)$ & .82 & $3.51(0.79)$ & .78 & $4.46(1.10)$ & .79 \\
\hline \multicolumn{7}{|l|}{ External networking } \\
\hline Building & $2.85(0.93)$ & .86 & $3.07(0.91)$ & .85 & $4.41(1.15)$ & .85 \\
\hline Maintaining & $2.47(0.94)$ & .79 & $2.50(0.71)$ & .82 & $3.90(1.33)$ & .82 \\
\hline Using & $2.73(0.90)$ & .88 & $2.93(0.89)$ & .86 & $4.19(1.19)$ & .85 \\
\hline Response options & $1-5$ & & $1-5$ & & $1-6$ & \\
\hline Sample size $N$ & 137 & & 123 & & 893 & \\
\hline
\end{tabular}




\section{Table 3}

Descriptive Statistics, Internal Consistencies, and Correlations of Study 1, Sample 2 Variables

\begin{tabular}{|c|c|c|c|c|c|c|c|c|c|c|c|c|c|c|c|}
\hline & $M$ & $S D$ & 1) & 2) & 3) & 4) & 5) & 6) & 7) & 8) & 9) & 10) & 11) & 12) & 13) \\
\hline 1) Internal networking & 3.38 & 0.64 & $(.84)$ & & & & & & & & & & & & \\
\hline 2) External networking & 2.83 & 0.77 & $.65^{* *}$ & $(.91)$ & & & & & & & & & & & \\
\hline 3) Age & 38.45 & 12.49 & $-.23^{*}$ & -.13 & - & & & & & & & & & & \\
\hline 4) Gender ${ }^{a}$ & 0.57 & 0.50 & $.20^{*}$ & .03 & $-.23^{*}$ & - & & & & & & & & & \\
\hline 5) Education ${ }^{b}$ & 2.46 & 0.74 & .18 & $.20^{*}$ & $-.28^{*}$ & .00 & & & & & & & & & \\
\hline 6) Extraversion & 3.47 & 0.50 & $.32^{* *}$ & $.30^{* *}$ & .00 & .16 & .02 & $(.78)$ & & & & & & & \\
\hline 7) Self-Monitoring & 1.39 & 0.17 & $.19^{*}$ & $.19^{*}$ & $-.19^{*}$ & .03 & .03 & $.21^{*}$ & $(.66)$ & & & & & & \\
\hline 8) Self esteem & 3.41 & 0.42 & .11 & .09 & $.26^{* *}$ & .00 & .13 & $.48^{* *}$ & -.14 & $(.82)$ & & & & & \\
\hline 9) Achievement Motivation & 2.91 & 0.54 & $.33^{* *}$ & $.21^{*}$ & $-.22^{*}$ & $.19^{*}$ & .06 & .08 & .12 & -.11 & $(.77)$ & & & & \\
\hline 10) Career Satisfaction & 4.75 & 1.03 & $.20^{*}$ & $.18^{\dagger}$ & -.11 & .08 & .06 & .02 & .05 & .03 & $.35^{* *}$ & $(.79)$ & & & \\
\hline 11) Hierarchical position & 55.60 & 22.62 & .13 & $.16^{\dagger}$ & .08 & -.11 & .03 & .17 & .06 & .09 & .14 & $.30^{* * *}$ & - & & \\
\hline 12) Task interdependence & 3.16 & 0.84 & .13 & -.01 & -.13 & -.08 & .02 & .08 & .10 & -.14 & -.01 & -.04 & .01 & $(.71)$ & \\
\hline 13) Autonomy & 3.76 & 0.77 & $.18^{*}$ & .09 & .06 & -.11 & .08 & .11 & $-.18^{*}$ & $.25^{* *}$ & $.20^{*}$ & $.26^{* *}$ & $.43^{* *}$ & $-.19^{*}$ & $(.79)$ \\
\hline
\end{tabular}

Note. $120 \leq N \leq 123$. Internal consistencies in parentheses on diagonal.

${ }^{\mathrm{a}} 0=$ male, $1=$ female. ${ }^{\mathrm{b}} 1=$ lower secondary education, $2=$ upper secondary, and $3=$ tertiary education according to ISCED standards.

${ }^{*} p<.05$, two-tailed. ${ }^{* *} p<.01$, two-tailed. ${ }^{\dagger} p<.05$, one-tailed. 
Table 4

Hierarchical Regression of Networking on Job/Task and Personality Variables from Sample 2

\begin{tabular}{|c|c|c|c|c|c|c|}
\hline & \multicolumn{3}{|c|}{ Internal Networking } & \multicolumn{3}{|c|}{ External Networking } \\
\hline & $\beta$ & $\beta$ & $\beta$ & $\beta$ & $\beta$ & $\beta$ \\
\hline Gender $^{\mathrm{a}}$ & $.16^{+}$ & $.21^{*}$ & .13 & -.01 & .02 & -.06 \\
\hline Age & $-.19^{*}$ & $-.17^{+}$ & -.14 & -.13 & -.13 & -.10 \\
\hline Job/Task variables & & & & & & \\
\hline Hierarchical position & & .07 & .01 & & .15 & .09 \\
\hline Task interdependence & & $.19^{*}$ & $.16^{+}$ & & .03 & -.01 \\
\hline Autonomy & & $.23^{*}$ & .15 & & .06 & -.01 \\
\hline Personality Variables & & & & & & \\
\hline Extraversion & & & $.19^{\dagger}$ & & & $.25^{*}$ \\
\hline Self-Monitoring & & & .11 & & & .08 \\
\hline Self esteem & & & .08 & & & .02 \\
\hline Achievement Motivation & & & $.24^{* *}$ & & & $.17^{\dagger}$ \\
\hline $\mathrm{R}^{2}$ & $.07^{*}$ & $.16^{* *}$ & $.28^{* *}$ & .02 & .05 & $.15^{*}$ \\
\hline $\mathrm{F}$ & 4.71 & 4.40 & 4.78 & 0.92 & 1.13 & $2.14^{*}$ \\
\hline$\Delta \mathrm{R}^{2}$ & & $.09^{*}$ & $.12^{* *}$ & & .03 & $.10^{*}$ \\
\hline$\Delta \mathrm{F}$ & & 3.95 & 4.58 & & 1.26 & $3.29^{*}$ \\
\hline
\end{tabular}

Note. $N=121$.

${ }^{\mathrm{a}} 0=$ male, 1 = female.

${ }^{*} p<.05$, two-tailed. ${ }^{* *} p<.01$, two-tailed. ${ }^{\dagger} p<.05$, one-tailed. 
Table 5

Results from Confirmatory Factor Analysis in Study 2

\begin{tabular}{|c|c|c|c|c|c|c|}
\hline & $C h i^{2}(d f)$ & RMSEA & SRMR & CFI & PNFI & CAIC \\
\hline 1) 1 Factor & $2821.23(135)$ & 0.15 & 0.100 & 0.88 & 0.77 & 3101.84 \\
\hline 2) 2 Factors (internal vs. external) & $1695.36(134)$ & 0.11 & 0.08 & 0.93 & 0.81 & 1983.76 \\
\hline 3) 3 Factors (building, maintaining, using) & $2462.63(132)$ & 0.14 & 0.100 & 0.89 & 0.77 & 2766.62 \\
\hline 4) 5 Factors $^{\mathrm{a}}$ & $609.08(113)$ & 0.070 & 0.064 & 0.98 & 0.72 & 1061.16 \\
\hline 5) 6 Factors $^{b}$ & $641.35(121)$ & 0.069 & 0.049 & 0.98 & 0.77 & 1030.08 \\
\hline 6) 6 factors $^{\mathrm{b}}$ and $1 \mathrm{G}-$ Factor & $1030.22(129)$ & 0.088 & 0.082 & 0.96 & 0.80 & 1357.60 \\
\hline $\begin{array}{l}\text { 7) } 6 \text { Factors }^{\mathrm{a}} \& 2 \text { G-Factors } \\
\text { external) }\end{array}$ & $852.90(129)$ & 0.079 & 0.079 & 0.97 & 0.81 & 1180.27 \\
\hline
\end{tabular}

Note. $N=893$.

a This model represents within item multidimensionality with two sets of factors: a) two correlated factors of internal vs. external networking and b) three correlated factors of building, maintaining, and using contacts. However, the two sets are uncorrelated (i.e., no correlation between internal networking and building contacts). ${ }^{b}$ The six factors are (1) building internal contacts, (2) maintaining internal contacts, (3) using internal contacts, (4) building external contacts, (5) maintaining external contacts, and (6) using external contacts. ${ }^{\mathrm{c}}$ A Heywood case occurred in this model with the factor loading of the maintaining internal contacts factor on the higher order factor exceeding 1.0. In the model presented, the error variance of the maintaining internal contacts factor was restricted to zero. 


\section{Table 6}

Descriptive Statistics and Correlations of Study 2 Variables

\begin{tabular}{|c|c|c|c|c|c|c|c|c|c|c|c|c|c|c|c|c|c|c|}
\hline & $M$ & $S D$ & 1) & 2) & 3) & 4) & 5) & 6) & 7) & 8) & 9) & 10) & 11) & 12) & 13) & 14) & 15) & 16) \\
\hline 1) Internal networking & 4.30 & 0.89 & $(.85)$ & & & & & & & & & & & & & & & \\
\hline 2) External networking & 4.16 & 1.08 & $.58^{* *}$ & $(.91)$ & & & & & & & & & & & & & & \\
\hline 3) Age & 33.31 & 5.34 & .05 & -.02 & - & & & & & & & & & & & & & \\
\hline 4) Gender ${ }^{a}$ & 0.52 & 0.50 & -.03 & .02 & -.05 & & & & & & & & & & & & & \\
\hline 5) Career commitment & 4.17 & 0.96 & $.19^{* *}$ & $.30^{* *}$ & $-.14^{* *}$ & .04 & $(.81)$ & & & & & & & & & & & \\
\hline $\begin{array}{l}\text { 6) Boundaryless career } \\
\text { attitude }\end{array}$ & 2.94 & 1.24 & $.08^{*}$ & $.14^{* *}$ & -.06 & .06 & $.17^{* *}$ & $(.80)$ & & & & & & & & & & \\
\hline 7) Protean career attitude & 4.63 & 0.83 & $.13^{*}$ & $.06^{\dagger}$ & $-.11^{*}$ & -.04 & $.18^{* *}$ & $.12^{* *}$ & $(.80)$ & & & & & & & & & \\
\hline 8) Internal marketability & 3.49 & 1.15 & $.22^{* *}$ & $.15^{* *}$ & -.06 & $-.07^{*}$ & $.14^{* *}$ & $.07^{*}$ & $.19^{* *}$ & $(.77)$ & & & & & & & & \\
\hline 9) External marketability & 3.64 & 1.18 & $.19^{* *}$ & $.18^{* *}$ & $-.24^{* *}$ & $-.18^{* *}$ & $.19^{* *}$ & $.18^{* *}$ & $.24^{* *}$ & $.31^{* *}$ & $(.81)$ & & & & & & & \\
\hline 10) Career satisfaction & 4.24 & 0.97 & $.23^{* *}$ & $.20^{* *}$ & -.06 & -.04 & $.23^{* *}$ & $.07^{*}$ & $.21^{* *}$ & $.39^{* *}$ & $.23^{* *}$ & $(.81)$ & & & & & & \\
\hline 11) Extraversion & 3.71 & 1.27 & $.29^{* *}$ & $.29^{* *}$ & -.01 & $.14^{* *}$ & $.20^{* *}$ & $.17^{* *}$ & .04 & $.10^{* *}$ & $.14^{* *}$ & $.15^{* *}$ & $(.83)$ & & & & & \\
\hline 12) Conscientiousness & 5.08 & 0.84 & .05 & -.01 & .02 & $.18^{* *}$ & $.08^{*}$ & -.03 & $.10^{* *}$ & -.01 & -.01 & $.10^{*}$ & -.01 & $(.64)$ & & & & \\
\hline 13) Openness & 4.77 & 0.87 & $.23^{* *}$ & $.24^{* *}$ & $.10^{* *}$ & $.08^{*}$ & $.17^{* *}$ & $.21^{* *}$ & .05 & .04 & $.09^{* *}$ & $.08^{*}$ & $.27^{* *}$ & $.10^{* *}$ & $(.50)$ & & & \\
\hline 14) Agreeableness & 4.42 & 0.92 & .01 & -.01 & .06 & $.11^{* *}$ & -.05 & $-.12^{* *}$ & -.02 & $.07^{*}$ & $-.08^{*}$ & .01 & -.04 & $.11^{* *}$ & $.08^{*}$ & $(.38)$ & & \\
\hline 15) Neuroticism & 2.50 & 1.10 & $-.22^{* *}$ & $-.14^{* *}$ & .05 & $.24^{* *}$ & -.01 & $.13^{* *}$ & -.01 & -.07 & $-.17^{* *}$ & $-.23^{* *}$ & $-.19^{* *}$ & $-.15^{* *}$ & $-.20^{* *}$ & $-.08^{*}$ & $(.76)$ & \\
\hline 16) Network size & 3.92 & 2.23 & $.11^{*}$ & $.16^{* *}$ & .05 & $.24^{* *}$ & -.01 & $.13^{* *}$ & -.01 & -.07 & -.06 & -.03 & .06 & .02 & $.14^{* *}$ & .02 & .07 & - \\
\hline 17) Network constraint & 0.51 & 0.21 & $-.10^{*}$ & $-.14^{* *}$ & -.01 & $-.21^{* *}$ & -.01 & $.12^{* *}$ & -.01 & .07 & .01 & .02 & $-.09^{*}$ & -.03 & $-.09^{*}$ & -.01 & $-.09^{*}$ & $-.83^{* *}$ \\
\hline
\end{tabular}

Note. $888 \leq N \leq 893$ for all variables, but $N=511$ for network size and constraint. Internal consistencies in parentheses on diagonal.

${ }^{\mathrm{a}} 0=$ male, $1=$ female.

${ }^{*} p<.05 .^{* *} p<.01{ }^{\dagger} p<.05$, one-tailed. 


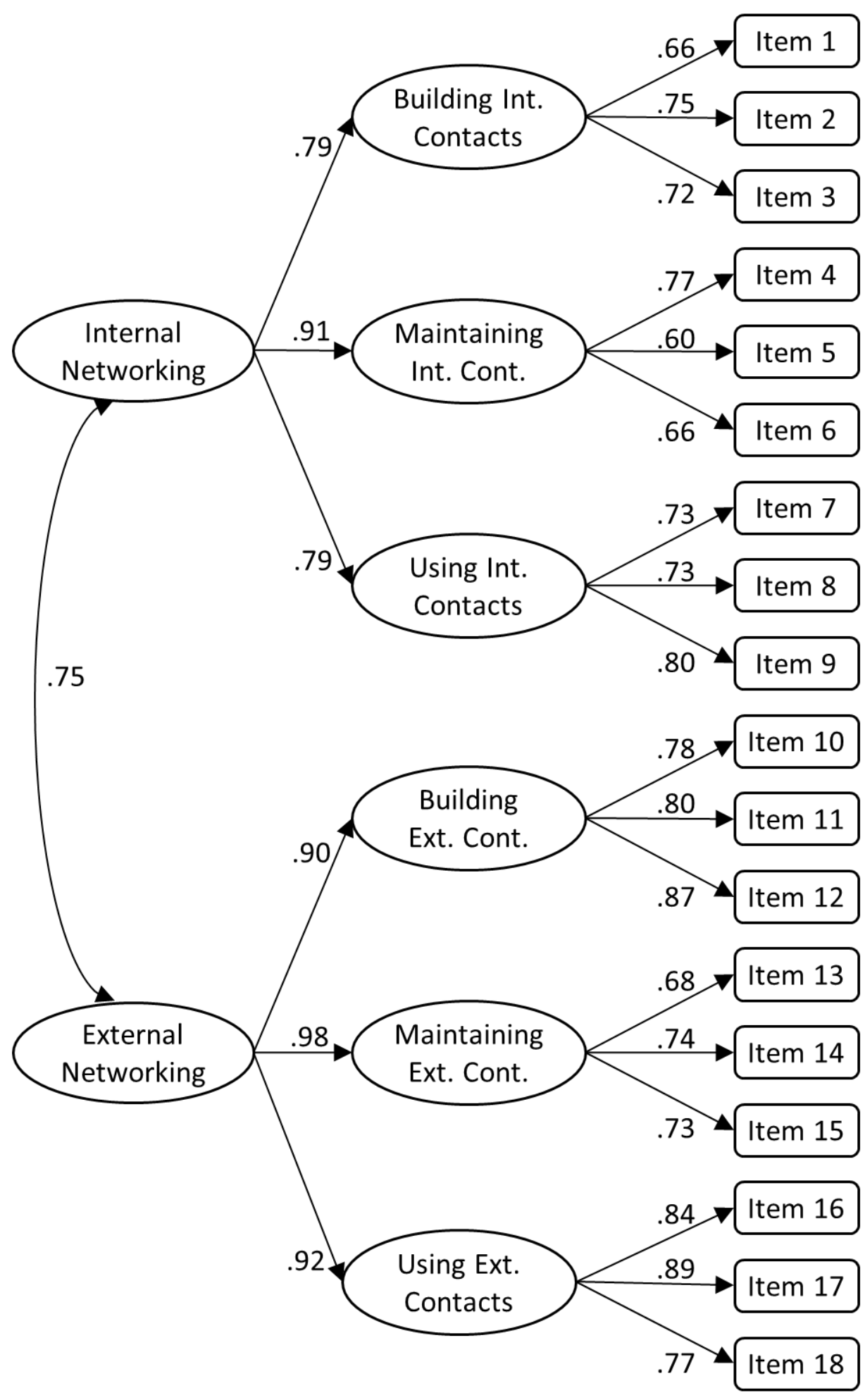

Figure 1. CFA Model with six first-order and two higher-order factors (Model 7 in Table 1, standardized solution). 